\title{
Insights from Therapeutic Studies for PrP Prion Disease
}

\author{
Kenta Teruya and Katsumi Doh-ura \\ Department of Neurochemistry, Tohoku University Graduate School of Medicine, Seiryo-cho, Aoba-ku, \\ Sendai 980-8575, Japan \\ Correspondence: doh-ura@med.tohoku.ac.jp
}

\begin{abstract}
Although an effective therapy for prion disease has not yet been established, many advances have been made toward understanding its pathogenesis, which has facilitated research into therapeutics for the disease. Several compounds, including flupirtine, quinacrine, pentosan polysulfate, and doxycycline, have recently been used on a trial basis for patients with prion disease. Concomitantly, several lead antiprion compounds, including compound B (compB), IND series, and anle138b, have been discovered. However, clinical trials are still far from yielding significantly beneficial results, and the findings of lead compound studies in animals have highlighted new challenges. These efforts have highlighted areas that need improvement or further exploration to achieve more effective therapies. In this work, we review recent advances in prion-related therapeutic research and discuss basic scientific issues to be resolved for meaningful medical intervention of prion disease.
\end{abstract}

Drion diseases, also called transmissible spongiform encephalopathies, in humans and animals, are rare neurodegenerative illnesses that are currently still incurable and fatal. Creutzfeldt-Jakob disease (CJD) (Creutzfeldt 1920; Jakob 1921) is the most representative human prion disease and comprises several clinicopathological subtypes (Parchi et al. 1999; Puoti et al. 2012). Most cases of CJD show a subacute progressive disease process after symptoms appear, making it difficult for patients to receive beneficial effects from therapeutic intervention. In this work, we will first review the history of medical intervention in prion diseases, which includes clinical trials and recent advances in therapeutic development. Next, we will examine the new insights provided by re- cent clinical trials and drug-discovery research. Finally, we will discuss the advances in basic science that need to be made to achieve better medical interventions for prion diseases in the near future.

\section{HISTORICAL OVERVIEW OF MEDICAL INTERVENTIONS FOR CJD}

Figure 1 shows the chronology of therapeutic development for CJD. In the early history of experimental CJD intervention (before 1990), preliminary experimental treatments (in addition to symptomatic treatments) were occasionally given to CJD patients in case report studies. The first drugs used to treat CJD patients were antivirals such as acyclovir (David et al. 1984;

Editor: Stanley B. Prusiner

Additional Perspectives on Prion Diseases available at www.perspectivesinmedicine.org

Copyright (C) 2017 Cold Spring Harbor Laboratory Press; all rights reserved; doi: 10.1101/cshperspect.a024430

Cite this article as Cold Spring Harb Perspect Med 2017;7:a024430 
K. Teruya and K. Doh-ura

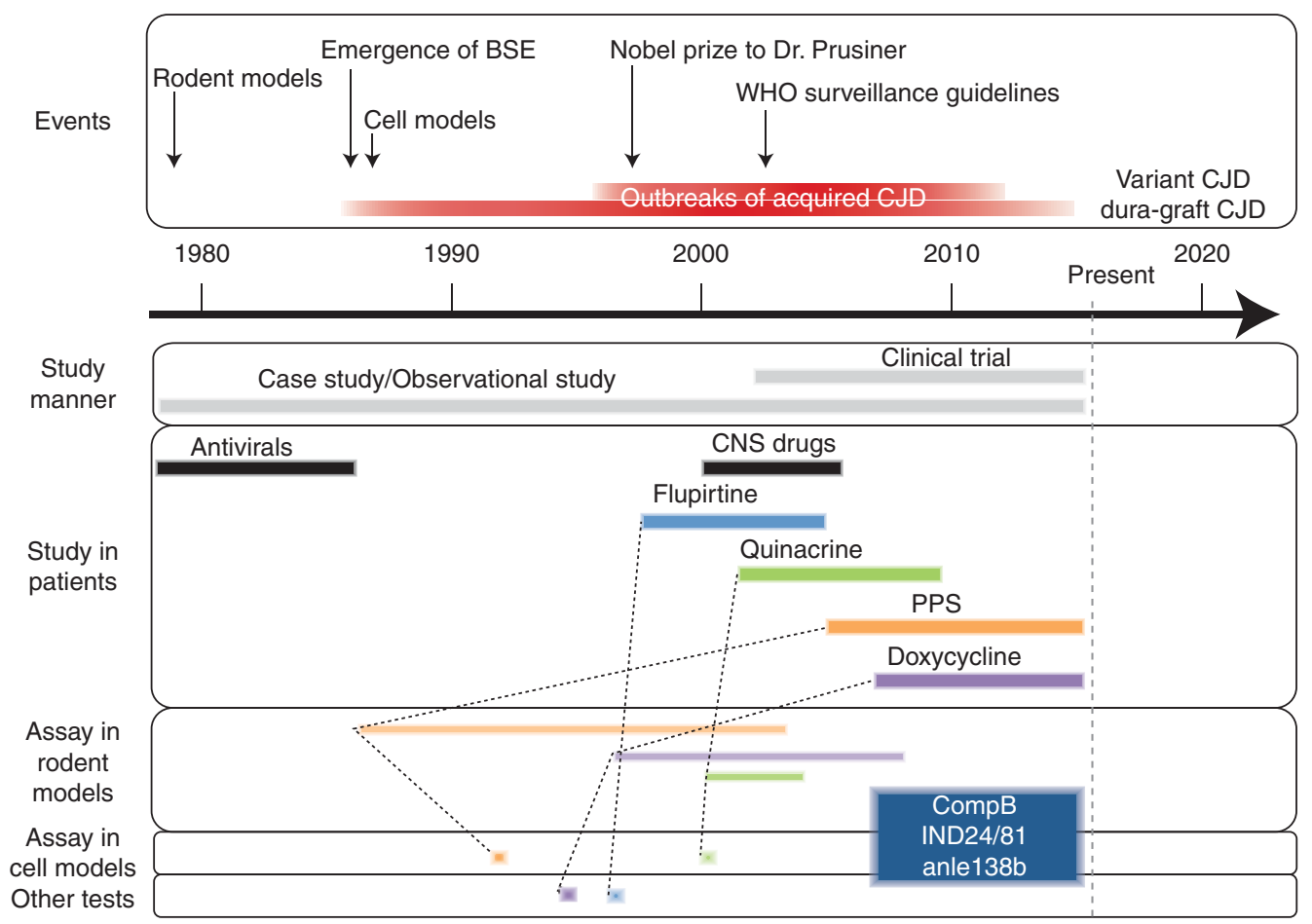

Figure 1. Chronology of therapeutic development for Creutzfeldt-Jakob disease (CJD). BSE, Bovine spongiform encephalopathy; WHO, World Health Organization; CNS, central nervous system; PPS, pentosane polysulfate.

Newman 1984), amantadine (Braham 1971; Norris 1972; Herishanu 1973; Sanders and Dunn 1973; Ratcliffe et al. 1975; Terzano et al. 1983; Neri et al. 1984), interferon (Kovanen et al. 1980), and vidarabine (Furlow et al. 1982). All of these drugs were used to address the transmissible features of CJD pathogens. The next group of drugs used to treat the disease were those that targeted agents affecting the central nervous system, including antidepressants (Dervaux et al. 2001), analgesics (Otto et al. 2004), and anticonvulsants (Imperiale et al. 2003), which were used to treat the encephalopathic features of the disease.

Following the discovery of prions as CJD pathogens (Prusiner 1998), many studies predominantly investigated compounds or biological materials that inhibited formation of the abnormal prion protein $\left(\mathrm{PrP}^{\mathrm{Sc}}\right)$ or that facilitated $\mathrm{PrP}^{\mathrm{Sc}}$ degradation to better understand the curious nature of the prion. Concurrently, two tragic events accelerated the search for spe- cific CJD remedies: the emergence of variant CJD (Will et al. 1996) and the prevalence of iatrogenic CJD (Nozaki et al. 2010). Because CJD and other types of human prion diseases are rare and difficult to diagnose at early stages, most reports regarding experimental intervention until the mid-2000s were from a single or few patients in the form of case reports or observational studies. However, it is very difficult to draw definite conclusions on the effectiveness of therapeutic agents because of the considerable variations in disease duration. Stewart et al. (2008) systematically summarized such reports and emphasized that disease course and treatment of all patients must be evaluated within a structured framework, preferably within randomized controlled trials.

Along with a stream of evidence-based medicine, several clinical trials have recently been performed within a structured framework, including flupirtine trials in Germany (Otto et al. 2004), quinacrine trials in the United 
Insights from Therapeutic Studies for PrP Prion Disease

Kingdom (Collinge et al. 2009) and United States (Geschwind et al. 2013), and doxycycline trials in Italy and France (Haïk et al. 2014). Table 1 summarizes these clinical trials and their results, and each trial is described in detail in the following section. It is important to note that recent CJD clinical trials have been multi-institutional or multinational collaborations of clinicians and researchers. Furthermore, outreach by patients and their families in support of nonprofit organizations has also been helpful in pushing therapeutic development forward.

\section{RECENT EXPERIMENTAL AND TRANSLATIONAL STUDIES IN CJD PATIENTS}

Researchers have made considerable effort to search for antiprion drugs or compounds using in silico screening, in vitro models, persistently prion-infected cell models, and prion-infected rodent models (Trevitt and Collinge 2006; Sim and Caughey 2009). In this section, we focus on drugs and compounds recently tested in CJD patients.

\section{Flupirtine}

Flupirtine (Fig. 2A) is a centrally acting, nonopioid analgesic found to have cytoprotective activity in vitro (Raffa and Pergolizzi 2012). This activity was also shown in a cell-viability assay against toxic PrP 106-126 aggregates, reminiscent of $\mathrm{PrP}^{\mathrm{Sc}}$ (Perovic et al. 1997). Flupirtine is a well-established drug-a randomized double-blind clinical trial of 28 CJD patients started in Germany in 1997 (Otto et al. 2004). It was concluded that flupirtine has beneficial effects on cognitive function but no significant effects on survival (Otto et al. 2004).

\section{Quinacrine}

Quinacrine (Fig. 2B) was discovered to inhibit $\mathrm{PrP}^{\mathrm{Sc}}$ formation in prion-infected cell models (Doh-ura et al. 2000; Korth et al. 2001). Thereafter, stereochemical (Ryou et al. 2003) and structure-activity relationship studies (Murakami-Kubo et al. 2004; Nguyen et al. 2008, 2011) were conducted. Aliphatic side-chain bonding to nitrogen at position 9 of the tricyclic scaffold of quinacrine is one of the key structures conferring potency in prion-infected cell models. However, quinacrine treatment was found to show no beneficial effects in prioninfected rodent models (Collins et al. 2002; Barret et al. 2003), even when administered by cerebroventricular infusion (Doh-ura et al. 2004). Kocisko and Caughey (2006) also showed the ineffectiveness of mefloquine, an antimalarial drug approved by the U.S. Food and Drug Administration that crosses the blood-brain barrier (Kocisko and Caughey 2006). It is interesting to note that quinacrine eliminates and/or modifies a specific subset of $\mathrm{PrP}^{\mathrm{Sc}}$ conformers, resulting in the survival of drug-resistant $\mathrm{PrP}^{\mathrm{Sc}}$ conformers (Ghaemmaghami et al. 2009) or selective amplification of drug-modified $\mathrm{PrP}^{\mathrm{Sc}}$ conformers (Bian et al. 2014).

Quinacrine has also been used for CJD patients in several observational studies (Kobayashi et al. 2003; Scoazec et al. 2003; Benito-León 2004; Haik et al. 2004; Nakajima et al. 2004; Satoh et al. 2004; Bertrand et al. 2005; Martínez-Lage et al. 2005; Wroe et al. 2006) that appeared after widespread media reports about a variant CJD patient who tentatively showed rapid improvement of neurological symptoms after quinacrine administration. However, the results of these studies were controversial. Tentative improvements in mental and neurological symptoms observed in some patients were regarded as part of an adverse reaction in the central nervous system, and the medication was discontinued by many patients because of its noxious effects (e.g., liver toxicity and bone marrow aplasia). A large-scale clinical trial of quinacrine used in an open-labeled, patientpreference manner (PRION-1 study) was launched in the United Kingdom in 2004 and included 107 patients with sporadic, iatrogenic, variant, or familial CJD (Collinge et al. 2009). This study concluded that there was no difference in mortality between the treated and untreated groups. Another clinical trial of quinacrine conducted in the United States from 2005 to 2009 in a double-blind, placebo-controlled, stratified-randomization manner concluded that quinacrine did not increase survival of 
K. Teruya and K. Doh-ura
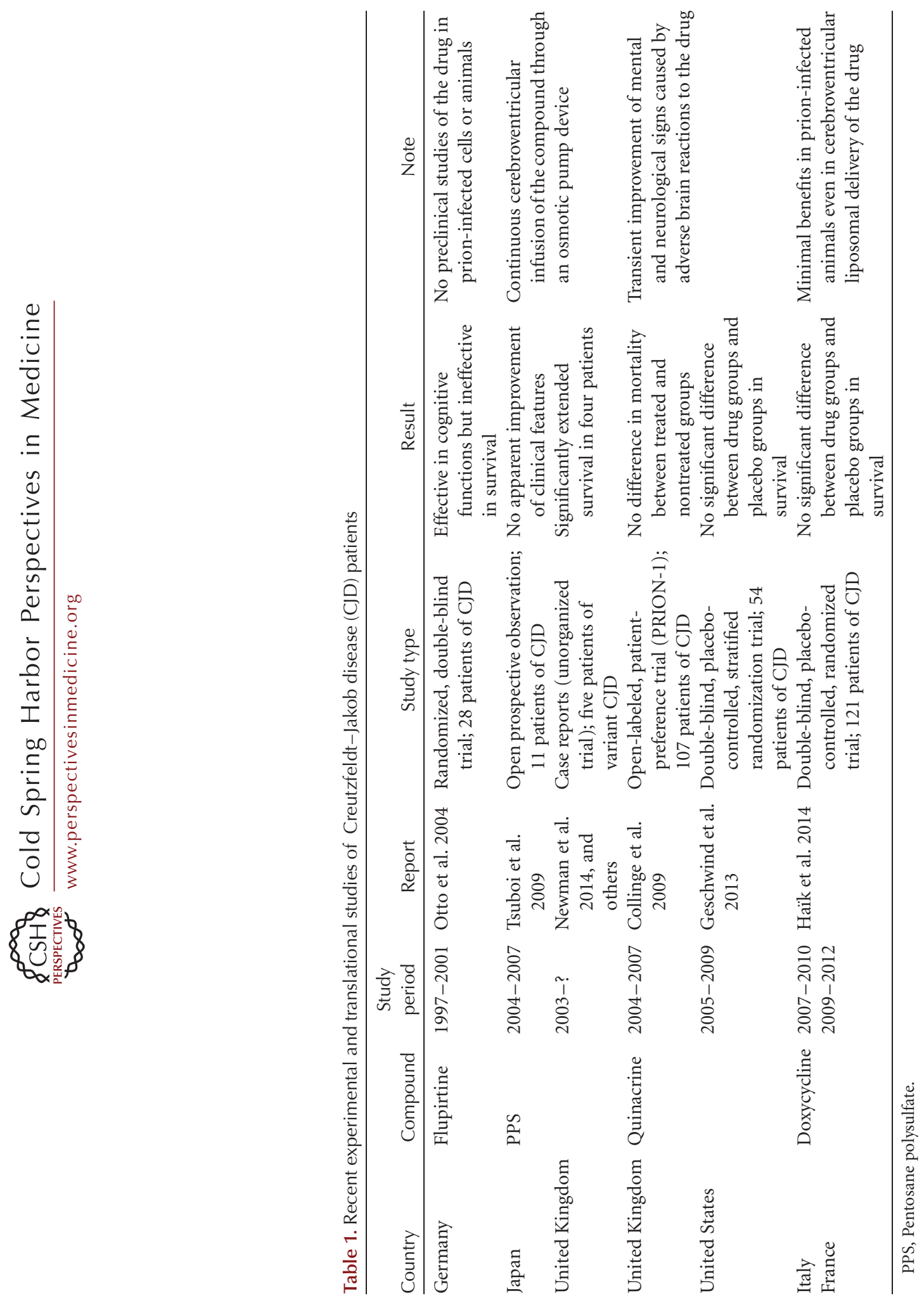
Insights from Therapeutic Studies for PrP Prion Disease
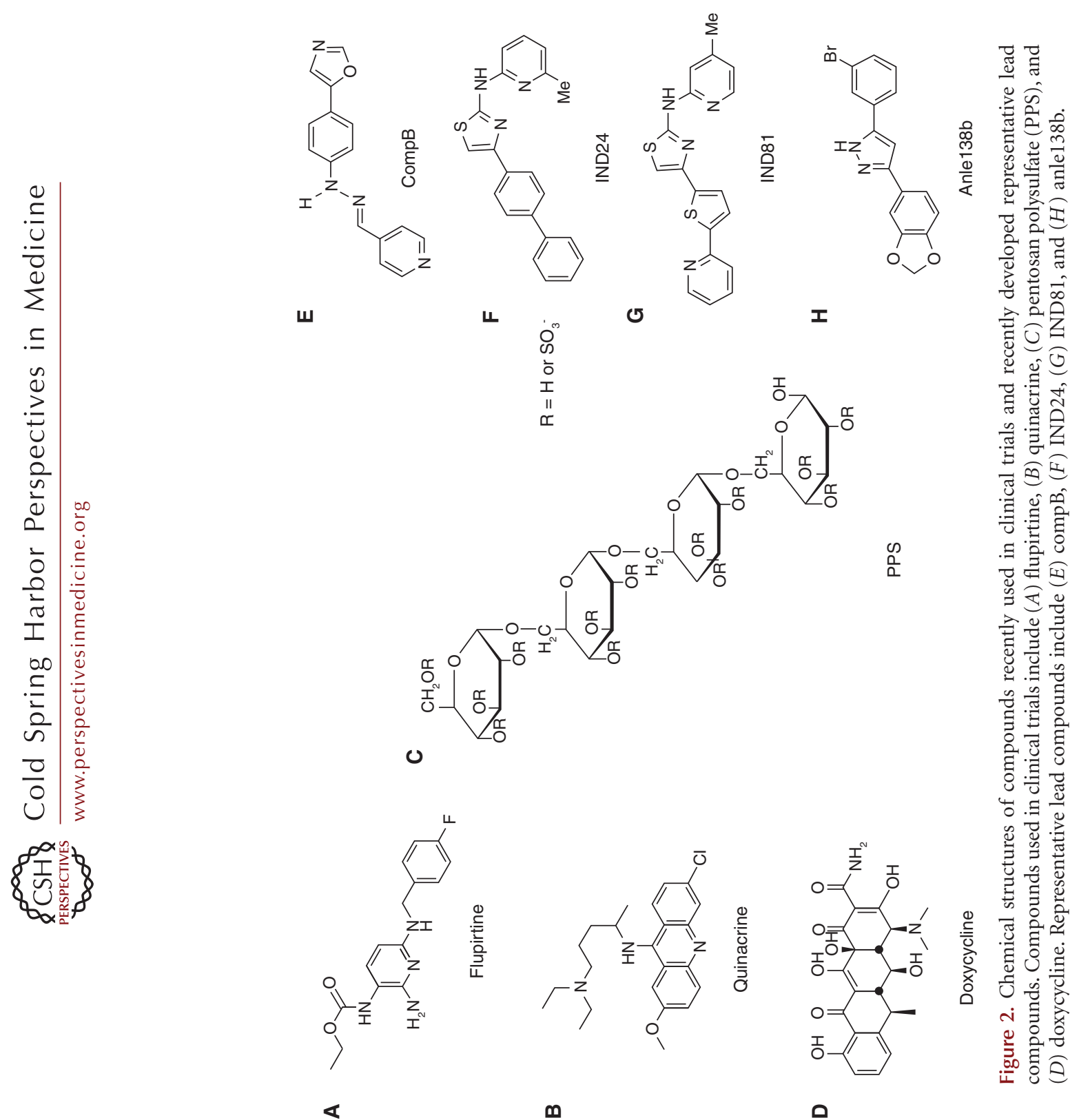
sporadic CJD patients compared with the placebo (Geschwind et al. 2013).

\section{Pentosan Polysulfate (PPS)}

Farquhar and Dickinson (1986) injected sulfated glycans, such as dextran sulfate and PPS, intraperitoneally or intravenously in peripherally prion-infected animals and found that these compounds inhibit prion replication in the lymphoreticular system and prolong incubation periods within the animals. Subsequently, Caughey and Raymond (1993) reported that these sulfated glycans inhibit $\mathrm{PrP}^{\mathrm{Sc}}$ formation in prion-infected cells by interacting with normal $\left(\mathrm{PrP}^{\mathrm{C}}\right)$ or abnormal $\left(\mathrm{PrP}^{\mathrm{Sc}}\right)$ prion-protein isoforms. As another example of polyanionic macromolecules, dietary seaweed fucoidan, a complex sulfated fucosylated polysaccharide, was also reported to delay disease onset in enterally prion-infected animals when administered orally (Doh-ura et al. 2007a).

PPS (Fig. 2C) is a sulfated semisynthetic polysaccharide with a heparin-like nature. Because of its highly charged polymeric structure, PPS does not penetrate the blood-brain barrier when administered orally or parenterally. To solve this issue, Doh-ura et al. (2004) performed cerebroventricular administration of PPS through an infusion-pump device. Continuous administration directly into the brain suppressed $\mathrm{PrP}^{\mathrm{Sc}}$ accumulation, neurodegenerative changes, and infectivity, and, consequently, prolonged the life spans of intracerebrally prion-infected animals, even when administered after the appearance of $\mathrm{PrP}^{\mathrm{Sc}}$ accumulation in the brain. However, PPS administered in this manner persisted around the infusion site and did not diffuse throughout the ventricular system-specifically, into the contralateral side of the brain where pathological changes were not well suppressed.

Based on the results of cerebroventricular PPS administration in animals, long-term cerebroventricular PPS treatment was then given to patients with prion diseases. After High Court hearings in the United Kingdom supported this treatment method for variant CJD, five patients were treated with cerebroventricular PPS (Todd et al. 2005; Whittle et al. 2006; Parry et al. 2007; Rainov et al. 2007; Bone et al. 2008; Newman et al. 2014). Four of the five PPS-treated patients survived significantly longer than untreated patients. The survival periods of these five PPStreated patients were $16,45,84,105$, and 114 months. However, the mean survival of variant CJD patients was 17 months, and the maximum survival period of untreated patients was 40 months (Newman et al. 2014). From a postmortem study of a long-term CJD survivor, Newman et al. (2014) observed that treatment with cerebroventricular PPS did not reduce overall neuropathological changes in the brain and concluded that the reason for long-term survival of CJD patients treated with cerebroventricular PPS remains unclear; however, the effect of the treatment on disease pathology cannot be excluded.

Conversely, Tsuboi et al. (2009) concluded that cerebroventricular PPS treatment of 11 Japanese patients with sporadic, familial, or iatrogenic CJD produced no apparent improvements in clinical features. These results are apparently discordant with those of variant CJD, suggesting that PPS efficacy might vary with disease subtype. Terada et al. (2010) reported a case of sporadic CJD treated with cerebroventricular PPS in Japan, wherein they observed a reduction in the amount of $\mathrm{PrP}^{\mathrm{Sc}}$ in the brain, although overall neuropathological changes were not reduced. In addition, Honda et al. (2012) reported neuropathological findings of four cases treated with cerebroventricular PPS in Japan, wherein the results suggest that PPS possibly modifies the accumulation of $\mathrm{PrP}^{\mathrm{Sc}}$ oligomers and the protein expression profile of astrocytes.

\section{Doxycycline}

Discovery of doxycycline (Fig. 2D) for CJD treatment began with the investigation of a structurally similar molecule, $4^{\prime}$-iodo- $4^{\prime}$-deoxy-doxorubicin, which binds to amyloid fibrils and induces amyloid resorption in patients with systemic amyloidosis. Tagliavini et al. (1997) found a reduction in both protease resistance and infectivity of $\mathrm{PrP}^{\mathrm{Sc}}$ when co-incubated with $4^{\prime}$-iodo- $4^{\prime}$-deoxy-doxorubicin. Doxycy- 
Insights from Therapeutic Studies for PrP Prion Disease

cline and other tetracycline compounds were shown to have similar activity against $\mathrm{PrP}^{\mathrm{Sc}}$, but with much less toxicity, by a subsequent series of in vitro and in vivo studies (Tagliavini et al. 2000; Forloni et al. 2002; Barret et al. 2003). These analogs were shown to prolong survival of peripherally or intracerebrally prion-infected animals when administered peripherally or intracerebrally (De Luigi et al. 2008).

Following an observational study of a considerable number of patients with CJD, a multiinstitutional, double-blind randomized trial of 121 CJD patients treated with doxycycline versus placebo was conducted in Italy and France (Haik et al. 2014). The results, however, did not show a significant difference in survival or disease progression in patients from either group. Researchers have speculated that treatment with oral doxycycline after disease symptoms first appear is relatively ineffective. In fact, an animal study by De Luigi et al. (2008) showed that even cerebroventricular liposomal delivery of doxycycline had very limited effect when administered after animals began to show signs of disease. At present, another clinical trial of doxycycline in Italy is reportedly providing preventive treatment to persons carrying a genetic mutation associated with fatal familial insomnia (FFI), a type of familial prion disease (Forloni et al. 2015). However, no data on doxycycline efficacy in an animal model of FFI have ever been reported.

\section{RECENT ADVANCES IN THERAPEUTIC DEVELOPMENT}

Figure 3 is a representation of prion propagation and possible therapeutic targets. Therapeutic targets include inhibition of $\mathrm{PrP}^{\mathrm{C}}$ expression, enhancement of $\operatorname{PrP}^{\mathrm{C}}$ degradation, inhibition of $\mathrm{PrP}^{\mathrm{C}}-\mathrm{PrP}^{\mathrm{Sc}}$ interaction, inhibition of $\mathrm{PrP}^{\mathrm{Sc}}$ oligomer formation, and enhancement of $\mathrm{PrP}^{\mathrm{Sc}}$ degradation. All of these targets have been intensively studied to understand the enigmatic nature of prions. In addition to these targets, some cellular factors have been implicated as possible targets in $\mathrm{PrP}^{\mathrm{C}}$-mediated or $\mathrm{PrP}^{\mathrm{Sc}}$ induced neurodegenerative processes (MouilletRichard et al. 2000; Moreno et al. 2012; Pietri et al. 2013; Alleaume-Butaux et al. 2015). One

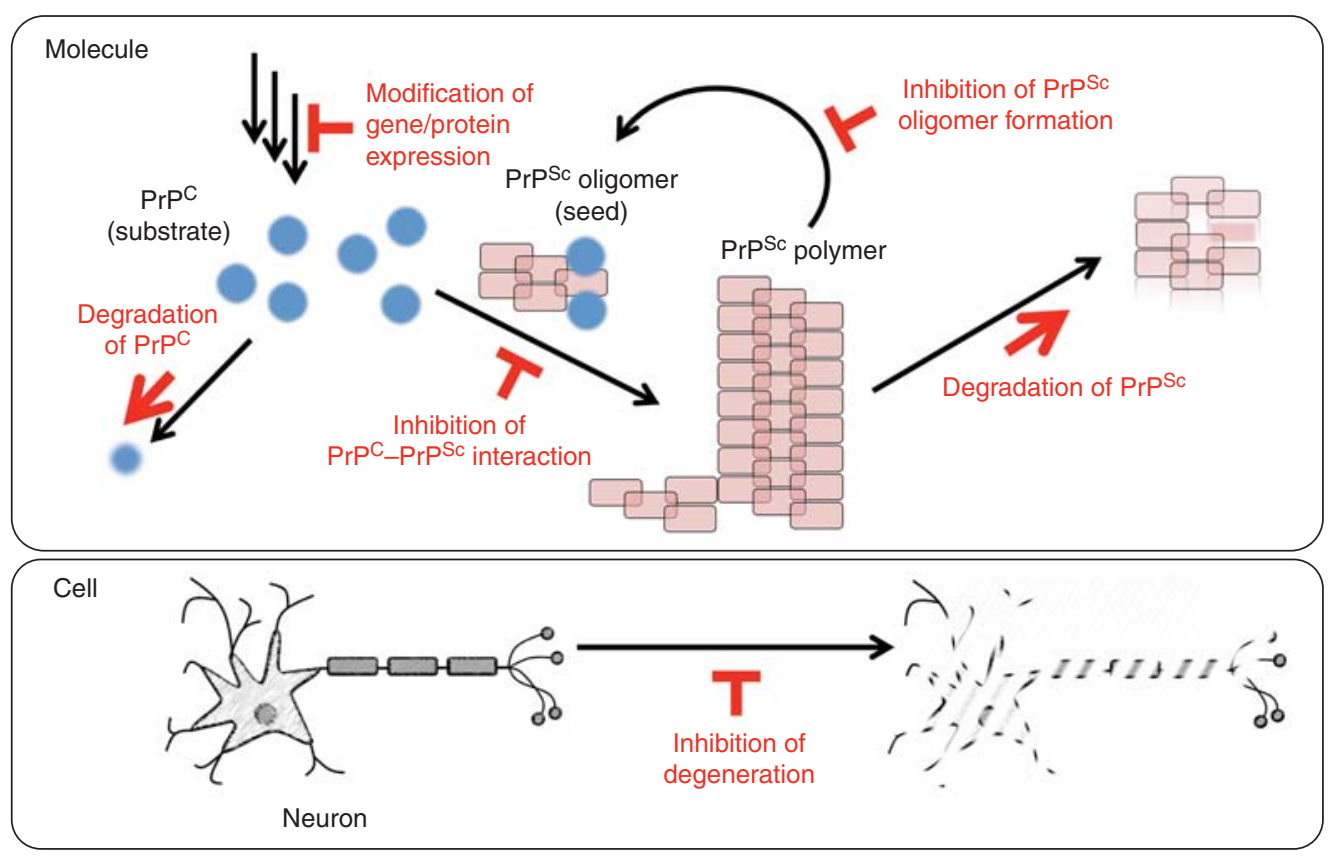

Figure 3. Schematic of possible targets for Creutzfeldt-Jakob disease (CJD) therapeutics. 
example was reported in an in vivo study of the growth arrest and DNA-damage-inducible protein GADD34, which promotes dephosphorylation of the $\alpha$-subunit of eukaryotic translation initiation factor 2 and reverses translational suppression caused by the prion infection-induced unfolded protein response in the endoplasmic reticulum (Moreno et al. 2012).

Thus far, $\operatorname{PrP}^{\mathrm{C}}$ has been the most attractive target for therapeutic development since it was reported that Prnp knockout mice are apparently healthy and resistant to prion infection (Büeler et al. 1993). In the Prnp-less background, residual infectivity disappeared within 4 days after inoculation, indicating efficient prion clearance in vivo (Aguzzi and Zhu 2012). Moreover, conditional knockout of Prnp expression halted disease progression and recovered certain brain functions even after disease onset (Mallucci et al. 2002, 2003). Subsequently, gene therapy studies of suppressed Prnp expression (Pfeifer et al. 2006; White et al. 2008) or immunotherapeutic targeting of $\operatorname{PrP}^{\mathrm{C}}$ (White et al. 2003; Song et al. 2008; Roettger et al. 2013) have been reported. Concurrently, compounds that suppress $\mathrm{PrP}^{\mathrm{C}}$ expression have also been investigated (Karapetyan et al. 2013). For example, the compound tacrolimus has been shown to reduce both membrane and intracellular $\mathrm{PrP}^{\mathrm{C}}$ levels by a nontranscriptional mechanism (Karapetyan et al. 2013), to suppress neurodegenerative processes in prioninfected animals by acting as a calcineurin inhibitor (Mukherjee et al. 2010), and to activate autophagy in both prion-infected cells and animals (Nakagaki et al. 2013).

Recent advancements in structural chemistry and biology have made it possible to identify important structural features of $\mathrm{PrP}^{\mathrm{C}}$, which has facilitated the investigation of interactions between $\operatorname{PrP}^{\mathrm{C}}$ and test compounds and has guided rational drug design (Kuwata 2013; Baral et al. 2014). Accordingly, Venko et al. (2014) computationally analyzed and summarized structure-activity relationships of small organic compounds using prion-infected cell-based assays. Kamatari et al. (2013) compared results of docking studies with the antiprion activity of designed compounds in prion-infected cell- based assays, and concluded that compounds potently inhibiting $\mathrm{PrP}^{\mathrm{Sc}}$ formation must not only bind to $\mathrm{PrP}^{\mathrm{C}}$ but also change the environment around the binding site to suppress the $\mathrm{PrP}^{\mathrm{C}}-\mathrm{PrP}^{\mathrm{Sc}}$ conversion reaction. Recently, Shirai et al. (2014) proposed a structural model of $\mathrm{PrP}^{\mathrm{Sc}}$ based on a comprehensive $\mathrm{PrP}^{\mathrm{C}}$ mutation study in prion-infected cell-based assays. Interfaces on which to build $\mathrm{PrP}^{\mathrm{C}}-\mathrm{PrP}^{\mathrm{Sc}}$ and $\mathrm{PrP}^{\mathrm{Sc}}-\mathrm{PrP}^{\mathrm{Sc}}$ interactions are highlighted in the literature.

Conversely, facilitating $\operatorname{PrP}^{\mathrm{Sc}}$ degradation is also an attractive target strategy. Autophagy is reported to facilitate $\mathrm{PrP}^{\mathrm{Sc}}$ clearance (Heiseke et al. 2010), and autophagy-related antiprion compounds, including astemizole (Karapetyan et al. 2013) and tacrolimus (Nakagaki et al. 2013), are reported to have certain effects in prion-infected animals. Conversely, Marzo et al. (2013) have recently reported that 4-hydroxytamoxifen conveys $\mathrm{PrP}^{\mathrm{C}}$ and $\mathrm{PrP}^{\mathrm{Sc}}$ to lysosomes independent of autophagy, suggesting the existence of a lysosomal degradation pathway for $\mathrm{PrP}^{\mathrm{Sc}}$ clearance.

\section{RECENTLY DEVELOPED REPRESENTATIVE LEAD COMPOUNDS}

In this section, we focus on three types of recently developed representative lead compounds that show remarkable inhibition of $\mathrm{PrP}^{\mathrm{Sc}}$ formation in prion-infected cells, as well as remarkable prolongation of survival periods in cerebrally prion-infected animals when the compounds are administered orally. The compounds include compound B (compB), IND series, and anle138b. All of these compounds are featured as having a planar structure comprising aromatic rings linked with conjugated bonds (Teruya and Doh-ura 2013).

\section{CompB}

The phenylhydrazine derivative 4-(oxazol-5yl)phenyl)-2-(( pyridin-4-yl)methylene)hydrazine, called compB (Fig. 2E) (Kawagoe et al. 2004), has been shown to be highly effective in prolonging the incubation of cerebrally prioninfected animals when administered orally (Ka- 
Insights from Therapeutic Studies for PrP Prion Disease

wasaki et al. 2007), with a brain-to-plasma concentration ratio of 2.6. Ten minutes after oral intake, $0.03 \%$ of the initial dose was found in the brain (Kawasaki et al. 2007; Suzuki N, unpubl.). Additionally, compB has no active efflux system, which hinders the clinical use of quinacrine. Together these characteristics make compB a suitable oral treatment for prion diseases. Orally administered compB prolonged incubation periods from $68.5 \pm 5.9$ days in untreated control mice to $154.3 \pm 19.9$ days in mice treated with $0.2 \%$ compB in their feed (approximately $300 \mathrm{mg} / \mathrm{kg} / \mathrm{d}$ ). Even at the terminal stage of the disease, orally administered compB maintained $\mathrm{PrP}^{\mathrm{Sc}}$ levels and infectivity titer of the brain at a remarkably low level. Although these features make compB a promising therapeutic compound, two shortcomings must be overcome: prion strain-dependent efficacy and inhibitory activity against several common P450 isozymes, which potentially cause a drug-drug interaction. Furthermore, high lability of an aryl hydrazine moiety (Hwu et al. 2004) may be a possible reason for the limited potency in vivo compared with that in vitro. Potency and pharmacokinetics in mice have been confirmed by others ( $\mathrm{Lu}$ et al. 2013). According to Lu et al. (2013), degradation of compB via Schiff base hydrolysis may generate a toxic metabolite and carcinogen. $\mathrm{Lu}$ et al. (2013) have shown that compB prolongs the survival of animals infected with the RML prion strain but is ineffective in animals infected with prions from MM1-type sporadic CJD, the most common CJD subtype. These data on prion strain specific efficacy of compB are consistent with those of Kawasaki et al. (2007).

\section{IND Series}

Two 2-aminothiazole compounds, IND24 (Fig. 2F, 4-(biphenyl-4-yl)-N-(6-methylpyridin-2-yl)thiazol-2-amine) and IND81 (Fig. 2G, 4-methyl- $N$-[4-[5-(2-pyridinyl)-2-thienyl]-2thiazolyl]-2-amine), were developed via a battery of large cell-based screenings, extensive structure-activity relationship studies, and pharmacokinetic analyses (Ghaemmaghami et al. 2014). One million diverse compounds were analyzed using an ELISA-based assay (Ghaemmaghami et al. 2010), and it was revealed that the 2 -aminothiazole scaffold exerts antiprion activity. Animal studies showed that compounds with a 2-aminothiazole scaffold were orally absorbed when properly formulated in liquid for rodents and achieved steady-state brain concentrations well in excess of their in vitro antiprion potencies (Gallardo-Godoy et al. 2011). Li et al. (2013) improved the potency of 2-aminothiazole compounds to maintain favorable in vivo pharmacokinetic profiles. Mice receiving IND24 or IND81 showed no adverse effects even at the highest dose of $210 \mathrm{mg} / \mathrm{kg} / \mathrm{d}$. Subsequently, a full pharmacokinetic investigation of IND24 and IND81 in mice (Silber et al. 2013) showed that IND24 prolonged the survival of mice infected with RML and ME7 prions from scrapie or prions from chronic wasting disease, but was ineffective against prions from MM1- and VV2-type sporadic CJD (Berry et al. 2013).

\section{Anle138b}

Anle138b (Fig. 2H, 3-(1,3-benzodioxol-5-yl)-5(3-bromophenyl)-1H-pyrazole) was discovered after screening a primary library comprising two million diverse drug-like compounds and a subsequent focused library of 150 compounds using a combination of methods (Wagner et al. 2013), including "scanning for intensely fluorescent targets," a novel method based on single-particle spectroscopy that allows targeting of oligomer formation (Bieschke et al. 2000; Bertsch et al. 2005). As a lead compound, anle138b has three more favorable features than compB: greater survival effects in mice; better pharmacokinetic properties (i.e., a longer halflife in the brain); and activity against all prion strains tested, including murine prions (RML and ME7 from scrapie and 301C from bovine spongiform encephalopathy) and human prions from sporadic and variant CJD. Therefore, anle138b may be the most promising drug candidate for the treatment of prion diseases at present. However, Berry et al. (2013) imply that the presence of a methylenedioxyphenol group in anle138b is a potential problem be- 
cause methylenedioxyphenol compounds were shown to produce neurotoxic or hepatotoxic effects (Murray 2000).

\section{INSIGHTS FROM THERAPEUTIC STUDIES ON HUMANS AND ANIMALS}

Although immeasurable efforts have made it feasible to conduct large-scale clinical trials, few meaningful outcomes have benefited CJD patients, as summarized in Table 1. The rapidly progressive disease process, the mechanism of which remains enigmatic, makes the timing of therapeutic intervention particularly difficult. At this moment, we are still very far from the goal of life-long survival with preserved quality of life, let alone a cure. In this section, we discuss the issues that should be resolved to achieve significantly beneficial intervention against prion disease.

\section{Preemptive Intervention}

One of the main reasons clinical trials commonly fail in terms of survival is delayed intervention. In fact, the more delayed the intervention in prion-infected animals, the less effective the antiprion compound is at prolonging survival (Doh-ura et al. 2004; Kawasaki et al. 2007). As shown in Figure 4, the most opportune time for therapeutic intervention of prion diseases is very early in the preclinical stage. At this stage, the odds of preventing or delaying disease onset are most favorable because exponentially accumulated amounts of prions almost reach a plateau in the brain before symptomatic disease onset (Prusiner 1987; Sandberg et al. 2014). Consequently, suitable preclinical diagnostic measurements are required for preemptive intervention.

\section{Preclinical Diagnosis}

Current diagnosis of CJD relies on a combination of results from magnetic resonance imaging, cerebrospinal fluid analysis, and electroencephalography (Zerr 2009; Wang et al. 2013). In addition, new technologies, such as quakinginduced conversion analysis for detecting an ultra-trace amount of $\operatorname{PrP}^{\mathrm{Sc}}$ in the cerebrospinal fluid (Atarashi et al. 2011; McGuire et al. 2012; Sano et al. 2013; Cramm et al. 2015; Orrú et al. 2015), nasal brushings (Orrú et al. 2014), urine (Moda et al. 2014), or blood (Orrú and Caughey 2011; Orrú et al. 2012), have presented new opportunities for early diagnosis. These recent advances in diagnostic techniques, whose sensitivity and specificity are $89 \%-97 \%$ and $100 \%$, respectively, are remarkable (Masters 2014; Moda et al 2014; Orrú et al. 2014, 2015). However, these techniques still may be insufficient to diagnose very early preclinical stages in healthy prion carriers or individuals predisposed to CJD. Further advances in this field, including

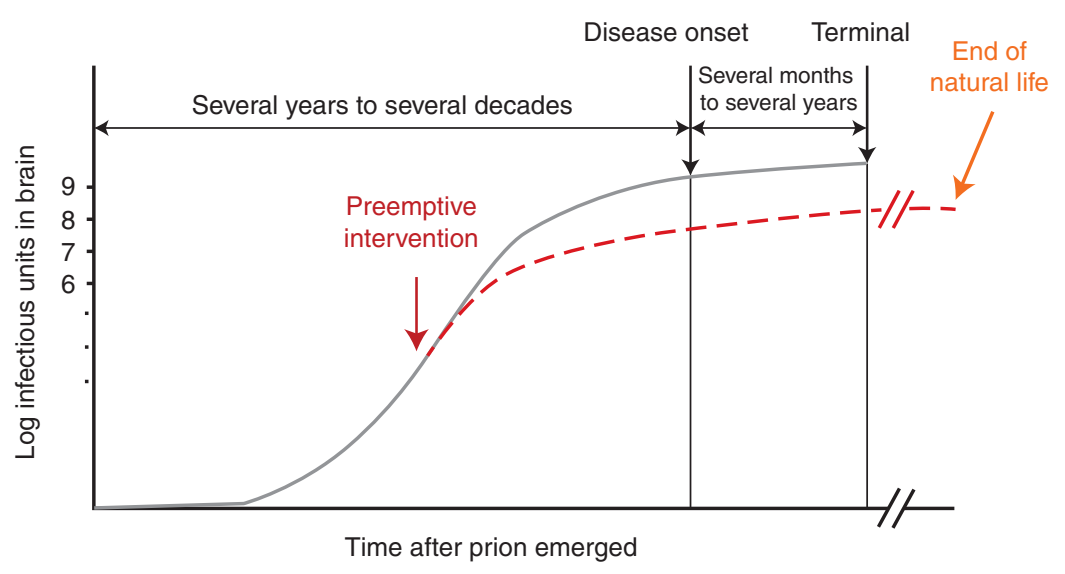

Figure 4. Schematic of the kinetics of prion accumulation in the brain and timing of medical intervention. 
Insights from Therapeutic Studies for PrP Prion Disease

discovery of surrogate markers, are necessary to detect healthy individuals at high risk.

Prion diseases have long incubation periods from infection to disease onset. It remains unclear whether the illness invariably occurs in those who have already been infected with prions, as this illness apparently only occurs in a certain portion of people predisposed to prions in any prion disease case. A genome-wide analysis has been performed to evaluate genetic predisposition to prion disease, but thus far no strong genetic factors other than PRNP have been disclosed. Many missense or insertional mutations in PRNP are linked to familial types of prion disease (Mastrianni 2010). In addition, polymorphic codon 129 of PRNP is partly associated with the risks of acquired prion diseases such as kuru, variant CJD, or iatrogenic CJD (Collinge et al. 1991, 1996), whereas polymorphic codon 127 and codon 219 are reportedly resistant to kuru (Mead et al. 2009; Asante et al. 2015) and sporadic CJD (Shibuya et al. 1998), respectively. However, carrying these types of $P R N P$ polymorphisms may not suggest whether a person will or will not develop the disease (Kobayashi et al. 2015). Even carrying disease-linked PRNP mutations does not necessarily mean that a person will inevitably develop the disease. For instance, no positive family history has ever been reported for patients with a valine-to-isoleucine mutation at codon 180 of PRNP, although this mutation is the most common $(40 \%)$ in patients with genetic prion diseases in Japan (Jin et al. 2004). Consequently, it is presumed that there are other genetic and environmental factors strongly affecting disease susceptibility. Understanding these factors will be useful for identifying those healthy individuals at high risk.

\section{Limitations of Single Compounds}

Another issue is the strain dependency of antiprion compounds, which causes the emergence of drug-resistant prion conformers in prion-infected cells or animals (Kawasaki et al. 2007; Ghaemmaghami et al. 2009; Berry et al. 2013; Miller-Vedam and Ghaemmaghami 2013). This issue is predicted based on similar drug-resis- tant phenomena in chemotherapy with antibiotic, antiviral, or anticancer drugs. However, the molecular mechanisms of strain-dependent activity and subsequent emergence of drug-resistant prion conformers remain to be elucidated. Disclosing antiprion pharmacophores targeting all prion strains is crucially important for the development of therapeutics for prion disease, considering that the most beneficial compound (anle138b) is incapable of halting disease progression even without the emergence of drugresistant prion conformers. Limitations of single-compound therapy are attributable to the induction of detoxification systems in the body, which is frequently an obstacle to monochemotherapy for cancers or viruses. Consequently, with reference to abundant knowledge of chemotherapy for cancer and infectious diseases, combination therapy using drugs with different structures and targets should also be considered for treating prion diseases. The beneficial effects of such an approach have been shown in principle in prion-infected rodents (Kocisko et al. 2006).

\section{A Combination of Multiple Targets}

As already described, many compounds or biological materials have been discovered to have antiprion activity related to the inhibition of $\mathrm{PrP}^{\mathrm{Sc}}$ formation or the enhancement of $\mathrm{PrP}^{\mathrm{Sc}}$ degradation through a combination of in silico, in vitro, prion-infected cell models, and prioninfected animal screening (Sim and Caughey 2009; Teruya et al. 2009). Among these models, prion-infected cell models have been the most frequently used since Congo red and polyanionic glycans were found to possess antiprion activity (Caughey and Race 1992; Caughey and Raymond 1993). In fact, our research group has identified dozens of antiprion compounds, including quinacrine and compB, using prion-infected cell models (Doh-ura et al. 2000, 2007b; Ishikawa et al. 2004, 2006; Murakami-Kubo et al. 2004; Kawatake et al. 2006; Kawasaki et al. 2007; Nguyen et al. 2008, 2011; Hamanaka et al. 2011, 2015; Teruya and Doh-ura 2013; Nishizawa et al. 2014). However, these cell models are not fully compatible with in vivo prion- 
infected neuronal cells. All persistently prioninfected cell models are mitotic and invulnerable to accumulated $\operatorname{PrP}^{\mathrm{Sc}}$, whereas prion-infected neuronal cells of the brain are postmitotic and presumably vulnerable to accumulated $\mathrm{PrP}^{\mathrm{Sc}}$. Therefore, more suitable prion-infected cell models are necessary for assaying not only $\mathrm{PrP}^{\mathrm{Sc}}$ formation and degradation but also $\mathrm{PrP}^{\mathrm{Sc}}$-induced neuronal cell death.

Regarding neurodegeneration, levels of $\mathrm{PrP}^{\mathrm{Sc}}$ accumulation and/or infectivity are not parallel to those of neurological deterioration (Prusiner 1987; Sandberg et al. 2014). In addition, a study of mice lacking a glycosylphosphatidylinositol anchor for $\operatorname{PrP}^{\mathrm{C}}$ has indicated that these mice survive for very long periods despite remarkable levels of $\mathrm{PrP}^{\mathrm{Sc}}$ or infectivity present in the brain (Chesebro et al. 2005). These data suggest that innovations in preemptive treatment strategies against $\mathrm{PrP}^{\mathrm{Sc}}$-induced neurodegenerative processes might be as or more important than those for inhibiting $\mathrm{PrP}^{\mathrm{Sc}}$ formation or facilitating its degradation. Even lifelong survival with a preserved quality of life may be possible irrespective of $\operatorname{PrP}^{\mathrm{Sc}}$ levels in the brain if the most effective specific treatments for the neurodegenerative processes could be introduced at very early preclinical stages. This wishful expectation, however, requires further evaluation.

\section{CONCLUDING REMARKS}

Large-scale clinical trials for prion diseases have been made feasible with a structured framework, and several lead candidates for antiprion therapy have been developed. In addition, efforts have been made to better understand the prion pathogen and its pathogenesis and to establish more sensitive and specific diagnostics, more susceptible experimental disease models, and more convenient drug-screening methods. Thus far, however, obtaining meaningful benefits from medical interventions after disease onset remains elusive. To gain really beneficial results, the timing of intervention should be shifted to an earlier preclinical stage of disease, wherein $\mathrm{PrP}^{\mathrm{Sc}}$ or infectivity in the brain remains low. Concomitantly, further advances are nec- essary to elucidate the prion-specific neurodegeneration mechanism, to identify endogenous and environmental factors susceptible or resistant to the disease, and to discover diagnostic surrogate markers for detecting healthy prion carriers. These advances could be made from recent research but will require continued innovative approaches and/or strategies.

\section{ACKNOWLEDGMENTS}

We thank Dr. Byron Caughey for his helpful suggestions. Our research discussed here is supported by Grants-in-Aid for Scientific Research from the Ministry of Education, Culture, Sports, Science and Technology of Japan; a grant from the Ministry of Health, Labour, and Welfare of Japan; a grant from the National Institute of Biomedical Innovation of Japan; and a grant from the Japan Agency for Medical Research and Development.

\section{REFERENCES}

Aguzzi A, Zhu C. 2012. Five questions on prion diseases. PLoS Pathog 8: e1002651.

Alleaume-Butaux A, Nicot S, Pietri M, Baudry A, Dakowski C, Tixador P, Ardila-Osorio H, Haeberlé AM, Bailly Y, Peyrin JM, et al. 2015. Double-edge sword of sustained ROCK activation in prion diseases through neuritogenesis defects and prion accumulation. PLos Pathog 11: e1005073.

Asante EA, Smidak M, Grimshaw A, Houghton R, Tomlinson A, Jeelani A, Jakubcova T, Hamdan S, Richard-Londt A, Linehan JM, et al. 2015. A naturally occurring variant of the human prion protein completely prevents prion disease. Nature 522: 478-481.

Atarashi R, Satoh K, Sano K, Fuse T, Yamaguchi N, Ishibashi D, Matsubara T, Nakagaki T, Yamanaka H, Shirabe S, et al 2011. Ultrasensitive human prion detection in cerebrospinal fluid by real-time quaking-induced conversion. Nat Med 17: 175-178.

Baral PK, Swayampakula M, Rout MK, Kav NNV, Spyracopoulos L, Aguzzi A, James MNG. 2014. Structural basis of prion inhibition by phenothiazine compounds. Structure 22: $291-303$.

Barret A, Tagliavini F, Forloni G, Bate C, Salmona M, Colombo L, De Luigi A, Limido L, Suardi S, Rossi G, et al. 2003. Evaluation of quinacrine treatment for prion diseases. J Virol 77: 8462-8469.

Benito-León J. 2004. Combined quinacrine and chlorpromazine therapy in fatal familial insomnia. Clin Neuropharmacol 27: 201-203.

Berry DB, Lu D, Geva M, Watts JC, Bhardwaj S, Oehler A, Renslo AR, DeArmond SJ, Prusiner SB, Giles K. 2013. 
Drug resistance confounding prion therapeutics. Proc Natl Acad Sci 110: E4160-E4169.

Bertrand A, Martinez-Almoyna L, De Broucker T. 2005. Hereditary Creutzfeldt-Jakob disease caused by a mutation at codon 200. Rev Neurol (Paris) 161: 351-354.

Bertsch U, Winklhofer KF, Hirschberger T, Bieschke J, Weber P, Hartl FU, Tavan P, Tatzelt J, Kretzschmar HA, Giese A. 2005. Systematic identification of antiprion drugs by high-throughput screening based on scanning for intensely fluorescent targets. J Virol 79: 7785-7791.

Bian J, Kang H-E, Telling GC. 2014. Quinacrine promotes replication and conformational mutation of chronic wasting disease prions. Proc Natl Acad Sci 111: 60286033.

Bieschke J, Giese A, Schulz-Schaeffer W, Zerr I, Poser S, Eigen M, Kretzschmar H. 2000. Ultrasensitive detection of pathological prion protein aggregates by dual-color scanning for intensely fluorescent targets. Proc Natl Acad Sci 97: 5468-5473.

Bone I, Belton L, Walker AS, Darbyshire J. 2008. Intraventricular pentosan polysulphate in human prion diseases: An observational study in the UK. Eur J Neurol 15: 458464.

Braham J. 1971. Jakob-Creutzfeldt disease: Treatment by amantadine. Br Med J 4: 212-213.

Büeler H, Aguzzi A, Sailer A, Greiner RA, Autenried P, Aguet M, Weissmann C. 1993. Mice devoid of PrP are resistant to scrapie. Cell 73: 1339-1347.

Caughey B, Race RE. 1992. Potent inhibition of scrapieassociated PrP accumulation by Congo red. J Neurochem 59: $768-771$.

Caughey B, Raymond GJ. 1993. Sulfated polyanion inhibition of scrapie-associated PrP accumulation in cultured cells. J Virol 67: 643-650.

Chesebro B, Trifilo M, Race R, Meade-White K, Teng C, LaCasse R, Raymond L, Favara C, Baron G, Priola S, et al. 2005. Anchorless prion protein results in infectious amyloid disease without clinical scrapie. Science 308: 1435-1439.

Collinge J, Palmer MS, Dryden AJ. 1991. Genetic predisposition to iatrogenic Creutzfeldt-Jakob disease. Lancet 337: 1441-1442.

Collinge J, Beck J, Campbell T, Estibeiro K, Will RG. 1996. Prion protein gene analysis in new variant cases of Creutzfeldt-Jakob disease. Lancet 348: 56.

Collinge J, Gorham M, Hudson F, Kennedy A, Keogh G, Pal S, Rossor M, Rudge P, Siddique D, Spyer M, et al. 2009. Safety and efficacy of quinacrine in human prion disease (PRION-1 study): A patient-preference trial. Lancet Neurol 8: 334-344.

Collins SJ, Lewis V, Brazier M, Hill AF, Fletcher A, Masters CL. 2002. Quinacrine does not prolong survival in a murine Creutzfeldt-Jakob disease model. Ann Neurol 52: 503-506.

Cramm M, Schmitz M, Karch A, Zafar S, Varges D, Mitrova E, Schroeder B, Raeber A, Kuhn F, Zerr I. 2015. Characteristic CSF prion seeding efficiency in humans with prion diseases. Mol Neurobiol 51: 396-405.

Creutzfeldt HG. 1920. Über eine eigenartige herdförmige erkrankung des zentralnervensystems (Vorläufige mitteilung) [About a rare focal disease of the central nervous system (preliminary communication)]. Z ges Neurol Psychiatr 57: 1-18.

David AS, Grant R, Ballantyne JP. 1984. Unsuccessful treatment of Creutzfeldt-Jakob disease with acyclovir. Lancet 1: 512-513.

De Luigi A, Colombo L, Diomede L, Capobianco R, Mangieri M, Miccolo C, Limido L, Forloni G, Tagliavini F, Salmona M. 2008. The efficacy of tetracyclines in peripheral and intracerebral prion infection. PLoS ONE 3: e1888.

Dervaux A, Vicart S, Lopes F, Le Borgne MH. 2001. Psychiatric manifestations of a new variant of CreutzfeldtJakob disease. Apropos of a case. Encephale 27: 194-197 (in French).

Doh-ura K, Iwaki T, Caughey B. 2000. Lysosomotropic agents and cysteine protease inhibitors inhibit scrapieassociated prion protein accumulation. J Virol 74: 48944897.

Doh-ura K, Ishikawa K, Murakami-Kubo I, Sasaki K, Mohri S, Race R, Iwaki T. 2004. Treatment of transmissible spongiform encephalopathy by intraventricular drug infusion in animal models. J Virol 78: 4999-5006.

Doh-ura K, Kuge T, Uomoto M, Nishizawa K, Kawasaki Y, Iha M. 2007a. Prophylactic effect of dietary seaweed Fucoidan against enteral prion infection. Antimicrob Agents Chemother 51: 2274-2277.

Doh-ura K, Tamura K, Karube Y, Naito M, Tsuruo T, Kataoka Y. 2007b. Chelating compound, chrysoidine, is more effective in both antiprion activity and brain endothelial permeability than quinacrine. Cell Mol Neurobiol 27: $303-316$.

Farquhar CF, Dickinson AG. 1986. Prolongation of scrapie incubation period by an injection of dextran sulphate 500 within the month before or after infection. J Gen Virol 67: 463-473.

Forloni G, Iussich S, Awan T, Colombo L, Angeretti N, Girola L, Bertani I, Poli G, Caramelli M, Grazia Bruzzone M, et al. 2002. Tetracyclines affect prion infectivity. Proc Natl Acad Sci 99: 10849-10854.

Forloni G, Tettamanti M, Lucca U, Albanese Y, Quaglio E, Chiesa R, Erbetta A, Villani F, Redaelli V, Tagliavini F, et al. 2015. Preventive study in subjects at risk of fatal familial insomnia: Innovative approach to rare diseases. Prion 9: $75-79$.

Furlow TW, Whitley RJ, Wilmes FJ. 1982. Repeated suppression of Creutzfeldt-Jakob disease with vidarabine. Lancet 2: $564-565$.

Gallardo-Godoy A, Gever J, Fife KL, Silber BM, Prusiner SB, Renslo AR. 2011. 2-Aminothiazoles as therapeutic leads for prion diseases. J Med Chem 54: 1010-1021.

Geschwind MD, Kuo AL, Wong KS, Haman A, Devereux G, Raudabaugh BJ, Johnson DY, Torres-Chae CC, Finley R, Garcia P, et al. 2013. Quinacrine treatment trial for sporadic Creutzfeldt-Jakob disease. Neurology 81: 2015-2023.

Ghaemmaghami S, Ahn M, Lessard P, Giles K, Legname G, DeArmond SJ, Prusiner SB. 2009. Continuous quinacrine treatment results in the formation of drug-resistant prions. PLoS Pathog 5: e1000673.

Ghaemmaghami S, May BCH, Renslo AR, Prusiner SB. 2010. Discovery of 2-aminothiazoles as potent antiprion compounds. J Virol 84: 3408-3412. 
Ghaemmaghami S, Russo M, Renslo AR. 2014. Successes and challenges in phenotype-based lead discovery for prion diseases. J Med Chem 57: 6919-6929.

Haïk S, Brandel JP, Salomon D, Sazdovitch V, DelasnerieLauprêtre N, Laplanche JL, Faucheux BA, Soubrié C, Boher E, Belorgey C, et al. 2004. Compassionate use of quinacrine in Creutzfeldt-Jakob disease fails to show significant effects. Neurology 63: 2413-2415.

Haïk S, Marcon G, Mallet A, Tettamanti M, Welaratne A, Giaccone G, Azimi S, Pietrini V, Fabreguettes J-R, Imperiale D, et al. 2014. Doxycycline in Creutzfeldt-Jakob disease: A phase 2, randomised, double-blind, placebocontrolled trial. Lancet Neurol 13: 150-158.

Hamanaka T, Sakasegawa Y, Ohmoto A, Kimura T, Ando T, Doh-ura K. 2011. Anti-prion activity of protein-bound polysaccharide $\mathrm{K}$ in prion-infected cells and animals. $\mathrm{Bi}$ ochem Biophys Res Commun 405: 285-290.

Hamanaka T, Nishizawa K, Sakasegawa Y, Teruya K, Doh-ura K. 2015. Structure-activity analysis and antiprion mechanism of isoprenoid compounds. Virology 486: 63-70.

Heiseke A, Aguib Y, Schatzl HM. 2010. Autophagy, prion infection and their mutual interactions. Curr Issues Mol Biol 12: 87-97.

Herishanu Y. 1973. Antiviral drugs in Jakob-Creutzfeldt disease. J Am Geriatr Soc 21: 229-231.

Honda H, Sasaki K, Minaki H, Masui K, Suzuki SO, Dohura K, Iwaki T. 2012. Protease-resistant PrP and PrP oligomers in the brain in human prion diseases after intraventricular pentosan polysulfate infusion. Neuropathol 32: $124-132$.

Hwu JR, Chieh Lin CC, Chuang SH, King KY, Su TR, Tsay SC. 2004. Aminyl and iminyl radicals from arylhydrazones in the photo-induced DNA cleavage. Bioorg Med Chem 12: 2509-2515.

Imperiale D, Bortolotto S, Cucatto A, Schiffer P, Cassano D, Buffa C. 2003. Levetiracetam control of myoclonus in a patient with Creutzfeldt-Jakob disease. Eur Neurol 49: 189-190.

Ishikawa K, Doh-ura K, Kudo Y, Nishida N, MurakamiKubo I, Ando Y, Sawada T, Iwaki T. 2004. Amyloid imaging probes are useful for detection of prion plaques and treatment of transmissible spongiform encephalopathies. J Gen Virol 85: 1785-1790.

Ishikawa K, Kudo Y, Nishida N, Suemoto T, Sawada T, Iwaki T, Doh-ura K. 2006. Styrylbenzoazole derivatives for imaging of prion plaques and treatment of transmissible spongiform encephalopathies. J Neurochem 99: 198-205.

Jakob A. 1921. Über eigenartige erkrankungen des zentralnervensystems mit bemerkenswertem anatomischen befunde. Z ges Neurol Psychiat 64: 147-228.

Jin K, Shiga Y, Shibuya S, Chida K, Sato Y, Konno H, Dohura K., Kitamoto T, Itoyama Y. 2004. Clinical features of Creutzfeldt-Jakob disease with V180I mutation. Neurology 62: 502-505.

Kamatari YO, Hayano Y, Yamaguchi K, Hosokawa-Muto J, Kuwata K. 2013. Characterizing antiprion compounds based on their binding properties to prion proteins: Implications as medical chaperones. Protein Sci 22: 22-34.

Karapetyan YE, Sferrazza GF, Zhou M, Ottenberg G, Spicer T, Chase P, Fallahi M, Hodder P, Weissmann C, Lasmézas CI. 2013. Unique drug screening approach for prion dis- eases identifies tacrolimus and astemizole as antiprion agents. Proc Natl Acad Sci 110:7044-7049.

Kawagoe K, Motoki K, Odagiri T, Suzuki N, Chen C-J, Mimura T. 2004. Hydrazone derivative. WIPO Publication No. WO/2004/087641. October 14.

Kawasaki Y, Kawagoe K, Chen C, Teruya K, Sakasegawa Y, Doh-ura K. 2007. Orally administered amyloidophilic compound is effective in prolonging the incubation periods of animals cerebrally infected with prion diseases in a prion strain-dependent manner. J Virol 81: 1288912898.

Kawatake S, Nishimura Y, Sakaguchi S, Iwaki T, Doh-ura K. 2006. Surface plasmon resonance analysis for the screening of anti-prion compounds. Biol Pharm Bull 29: $927-$ 932.

Kobayashi Y, Hirata K, Tanaka H, Yamada T. 2003. Quinacrine administration to a patient with Creutzfeldt-Jakob disease who received a cadaveric dura mater graft-An EEG evaluation. Rinsho Shinkeigaku 43: 403-408.

Kobayashi A, Teruya K, Matsuura Y, Shirai T, Nakamura Y, Yamada M, Mizusawa H, Mohri S, Kitamoto T. 2015. The influence of $P R N P$ polymorphisms on human prion disease susceptibility: An update. Acta Neuropathol 130: 159-170.

Kocisko DA, Caughey B. 2006. Mefloquine, an antimalaria drug with antiprion activity in vitro, lacks activity in vivo. J Virol 80: 1044-1046.

Kocisko DA, Caughey B, Morrey JD, Race RE. 2006. Enhanced antiscrapie effect using combination drug treatment. Antimicrob Agents Chemother 50: 3447-3449.

Korth C, May BCH, Cohen FE, Prusiner SB. 2001. Acridine and phenothiazine derivatives as pharmacotherapeutics for prion disease. Proc Natl Acad Sci 98: 9836-9841.

Kovanen J, Haltia M, Cantell K. 1980. Failure of interferon to modify Creutzfeldt-Jakob disease. $\mathrm{Br}$ Med J 280: 902.

Kuwata K. 2013. Logical design of medical chaperone for prion diseases. Curr Top Med Chem 13: 2432-2440.

Li Z, Silber BM, Rao S, Gever J, Bryant C, Gallardo-Godoy A, Dolghih E, Widjaja K, Elepano M, Jacobson MP, et al 2013. 2-Aminothiazoles with improved pharmacotherapeutic properties for treatment of prion disease. Chem Med Chem 8: 847-857.

Lu D, Giles K, Li Z, Rao S, Dolghih E, Gever JR, Geva M, Elepano ML, Oehler A, Bryant C, et al. 2013. Biaryl amides and hydrazones as therapeutics for prion disease in transgenic mice. J Pharmacol Exp Ther 347: 325-338.

Mallucci GR, Ratté S, Asante EA, Linehan J, Gowland I, Jefferys JGR, Collinge J. 2002. Post-natal knockout of prion protein alters hippocampal CA1 properties, but does not result in neurodegeneration. EMBO J 21: 202-210.

Mallucci G, Dickinson A, Linehan J, Klöhn P-C, Brandner S, Collinge J. 2003. Depleting neuronal PrP in prion infection prevents disease and reverses spongiosis. Science 302: 871-874.

Martínez-Lage JF, Rábano A, Bermejo J, Martínez Pérez M, Guerrero MC, Contreras MA, Lunar A. 2005. Creutzfeldt-Jakob disease acquired via a dural graft: Failure of therapy with quinacrine and chlorpromazine. Surg Neurol 64: $542-545$. 
Marzo L, Marijanovic Z, Browman D, Chamoun Z, Caputo A, Zurzolo C. 2013. 4-Hydroxytamoxifen leads to $\operatorname{PrP}^{\text {SC }}$ clearance by conveying both $\operatorname{PrP}^{\mathrm{C}}$ and $\operatorname{PrP}^{\mathrm{Sc}}$ to lysosomes independently of autophagy. J Cell Sci 126: 1345-1354.

Masters CL. 2014. Shaken, not sonicated? N Engl J Med 371: $571-572$.

Mastrianni JA. 2010. The genetics of prion diseases. Genet Med 12: 187-195.

McGuire LI, Peden AH, Orrú CD, Wilham JM, Appleford NE, Mallinson G, Andrews M, Head MW, Caughey B, Will RG, et al. 2012. RT-QuIC analysis of cerebrospinal fluid in sporadic Creutzfeldt-Jakob disease. Ann Neurol 72: $278-285$.

Mead S, Whitfield J, Poulter M, Shah P, Uphill J, Campbell T, Al-Dujaily H, Hummerich H, Beck J, Mein CA, et al. 2009. A novel protective prion protein variant that colocalizes with kuru exposure. N Engl J Med 361: 2056-2065.

Miller-Vedam L, Ghaemmaghami S. 2013. Strain specificity and drug resistance in anti-prion therapy. Curr Top Med Chem 13: 2397-2406.

Moda F, Gambetti P, Notari S, Concha-Marambio L, Catania M, Park KW, Maderna E, Suardi S, Haïk S, Brandel JP, et al. 2014. Prions in the urine of patients with variant Creutzfeldt-Jakob disease. N Engl J Med 371: 530-539.

Moreno JA, Radford H, Peretti D, Steinert JR, Verity N, Martin MG, Halliday M, Morgan J, Dinsdale D, Ortori CA, et al. 2012. Sustained translational repression by eIF $2 \alpha-\mathrm{P}$ mediates prion neurodegeneration. Nature 485: 507-511.

Mouillet-Richard S, Ermonval M, Chebassier C, Laplanche JL, Lehmann S, Launay JM, Kellermann O. 2000. Signal transduction through prion protein. Science 289: 19251928.

Mukherjee A, Morales-Scheihing D, Gonzalez-Romero D, Green K, Taglialatela G, Soto C. 2010. Calcineurin inhibition at the clinical phase of prion disease reduces neurodegeneration, improves behavioral alterations and increases animal survival. PLoS Pathog 6: e1001138.

Murakami-Kubo I, Doh-ura K, Ishikawa K, Kawatake S, Sasaki K, Kira J, Ohta S, Iwaki T. 2004. Quinoline derivatives are therapeutic candidates for transmissible spongiform encephalopathies. J Virol 78: 1281-1288.

Murray M. 2000. Mechanisms of inhibitory and regulatory effects of methylenedioxyphenyl compounds on cytochrome P450-dependent drug oxidation. Curr Drug Metab 1: 67-84.

Nakagaki T, Satoh K, Ishibashi D, Fuse T, Sano K, Kamatari YO, Kuwata K, Shigematsu K, Iwamaru Y, Takenouchi T, et al. 2013. FK506 reduces abnormal prion protein through the activation of autolysosomal degradation and prolongs survival in prion-infected mice. Autophagy 9: $1386-1394$.

Nakajima M, Yamada T, Kusuhara T, Furukawa H, Takahashi M, Yamauchi A, Kataoka Y. 2004. Results of quinacrine administration to patients with Creutzfeldt-Jakob disease. Dement Geriatr Cogn Disord 17: 158-163.

Neri G, Figà-Talamanca L, Di Battista GC, Lo Russo F. 1984. Amantadine in Creutzfeldt-Jakob disease. Review of the literature and case contribution. Riv Neurobiol 30: 47-56.

Newman PK. 1984. Acyclovir in Creutzfeldt-Jakob disease. Lancet 1: 793.
Newman PK, Todd NV, Scoones D, Mead S, Knight RSG, Will RG, Ironside JW. 2014. Postmortem findings in a case of variant Creutzfeldt-Jakob disease treated with intraventricular pentosan polysulfate. J Neurol Neurosurg Psychiatry 85: 921-924.

Nguyen THT, Lee CY, Teruya K, Ong WY, Doh-ura K, Go ML. 2008. Antiprion activity of functionalized 9-aminoacridines related to quinacrine. Bioorg Med Chem 16: 6737-6746.

Nguyen T, Sakasegawa Y, Doh-ura K, Go ML. 2011. Antiprion activities and drug-like potential of functionalized quinacrine analogs with basic phenyl residues at the 9amino position. Eur J Med Chem 46: 2917-2929.

Nishizawa K, Oguma A, Kawata M, Sakasegawa Y, Teruya K, Doh-ura K. 2014. Efficacy and mechanism of a glycoside compound inhibiting abnormal prion protein formation in prion-infected cells: Implications of interferon and phosphodiesterase 4D-interacting protein. J Virol 88: 4083-4099.

Norris FH. 1972. Amantadine in Jakob-Creutzfeldt disease. Br Med J 2: 349.

Nozaki I, Hamaguchi T, Sanjo N, Noguchi-Shinohara M, Sakai K, Nakamura Y, Sato T, Kitamoto T, Mizusawa H, Moriwaka F, et al. 2010. Prospective 10-year surveillance of human prion diseases in Japan. Brain 133: 3043-3057.

Orrú CD, Caughey B. 2011. Prion seeded conversion and amplification assays. Top Curr Chem 305: 121-133.

Orrú CD, Wilham JM, Vascellari S, Hughson AG, Caughey B. 2012. New generation QuIC assays for prion seeding activity. Prion 6: 147-152.

Orrú CD, Bongianni M, Tonoli G, Ferrari S, Hughson AG, Groveman BR, Fiorini M, Pocchiari M, Monaco S, Caughey B, et al. 2014. A test for Creutzfeldt-Jakob disease using nasal brushings. N Engl J Med 371: 519-529.

Orrú CD, Groveman BR, Hughson AG, Zanusso G, Coulthart M, Caughey B, 2015. Rapid and sensitive RT-QuIC detection of human Creutzfeldt-Jakob disease using cerebral spinal fluid. mBio 6: e2451-14.

Otto M, Cepek L, Ratzka P, Doehlinger S, Boekhoff I, Wiltfang J, Irle E, Pergande G, Ellers-Lenz B, Windl O, et al. 2004. Efficacy of flupirtine on cognitive function in patients with CJD: A double-blind study. Neurology 62: $714-718$.

Parchi P, Giese A, Capellari S, Brown P, Schulz-Schaeffer W, Windl O, Zerr I, Budka H, Kopp N, Piccardo P, et al. 1999. Classification of sporadic Creutzfeldt-Jakob disease based on molecular and phenotypic analysis of 300 subjects. Ann Neurol 46: 224-233.

Parry A, Baker I, Stacey R, Wimalaratna S. 2007. Long term survival in a patient with variant Creutzfeldt-Jakob disease treated with intraventricular pentosan polysulphate. J Neurol Neurosurg Psychiatry 78: 733-734.

Perovic S, Schröder HC, Pergande G, Ushijima H, Müller WEG. 1997. Effect of flupirtine on Bcl-2 and glutathione level in neuronal cells treated in vitro with the prion protein fragment (PrP106-126). Exp Neurol 147: 518524.

Pfeifer A, Eigenbrod S, Al-Khadra S, Hofmann A, Mitteregger G, Moser M, Bertsch U, Kretzschmar H. 2006. Lentivector-mediated RNAi efficiently suppresses prion protein and prolongs survival of scrapie-infected mice. $J$ Clin Invest 116: 3204-3210. 
Pietri M, Dakowski C, Hannaoui S, Alleaume-Butaux A, Hernandez-Rapp J, Ragagnin A, Mouillet-Richard S, Haik S, Bailly Y, Peyrin JM, et al. 2013. PDK1 decreases TACE-mediated $\alpha$-secretase activity and promotes disease progression in prion and Alzheimer's diseases. Nat Med 19: 1124-1131.

Prusiner SB. 1987. Prions and neurodegenerative diseases. N Engl J Med 317: 1571-1581.

Prusiner SB. 1998. Prions. Proc Natl Acad Sci 95: 1336313383.

Puoti G, Bizzi A, Forloni G, Safar JG, Tagliavini F, Gambetti P. 2012. Sporadic human prion diseases: Molecular insights and diagnosis. Lancet Neurol 11: 618-628.

Raffa RB, Pergolizzi JV Jr. 2012. The evolving understanding of the analgesic mechanism of action of flupirtine. J Clin Pharm Ther 37: 4-6.

Rainov NG, Tsuboi Y, Krolak-Salmon P, Vighetto A, Dohura K. 2007. Experimental treatments for human transmissible spongiform encephalopathies: Is there a role for pentosan polysulfate? Expert Opin Biol Ther 7: 713-726.

Ratcliffe J, Rittman A, WolfS, Verity MA. 1975. CreutzfeldtJakob disease with focal onset unsuccessfully treated with amantadine. Bull Los Angeles Neurol Soc 40: 18-20.

Roettger Y, Du Y, Bacher M, Zerr I, Dodel R, Bach J-P. 2013. Immunotherapy in prion disease. Nat Rev Neurol 9: 98 105.

Ryou C, Prusiner SB, Legname G. 2003. Cooperative binding of dominant-negative prion protein to kringle domains. J Mol Biol 329: 323-333.

Sandberg MK, Al-Doujaily H, Sharps B, De Oliveira MW, Schmidt C, Richard-Londt A, Lyall S, Linehan JM, Brandner S, Wadsworth JDF, et al. 2014. Prion neuropathology follows the accumulation of alternate prion protein isoforms after infective titre has peaked. Nat Commun 5: 4347.

Sanders WL, Dunn TL. 1973. Creutzfeldt-Jakob disease treated with amantidine. J Neurol Neurosurg Psychiatry 36: $581-584$.

Sano K, Satoh K, Atarashi R, Takashima H, Iwasaki Y, Yoshida M, Sanjo N, Murai H, Mizusawa H, Schmitz M, et al. 2013. Early detection of abnormal prion protein in genetic human prion diseases now possible using real-time QUIC assay. PLoS ONE 8: e54915.

Satoh K, Shirabe S, Eguchi K, Yamauchi A, Kataoka Y, Niwa M, Nishida N, Katamine S. 2004. Toxicity of quinacrine can be reduced by co-administration of P-glycoprotein inhibitor in sporadic Creutzfeldt-Jakob disease. Cell Mol Neurobiol 24: 873-875.

Scoazec JY, Krolak-Salmon P, Casez O, Besson G, Thobois S, Kopp N, Perret-Liaudet A, Streichenberger N. 2003. Quinacrine-induced cytolytic hepatitis in sporadic Creutzfeldt-Jakob disease. Ann Neurol 53: 546-547.

Shibuya S, Higuchi J, Shin RW, Tateishi J, Kitamoto T. 1998. Codon 219 Lys allele of PRNP is not found in sporadic Creutzfeldt-Jakob disease. Ann Neurol 43: 826-828.

Shirai T, Saito M, Kobayashi A, Asano M, Hizume M, Ikeda S, Teruya K, Morita M, Kitamoto T. 2014. Evaluating prion models based on comprehensive mutation data of mouse PrP. Structure 22: 560-571.

Silber BM, Rao S, Fife KL, Gallardo-Godoy A, Renslo AR, Dalvie DK, Giles K, Freyman Y, Elepano M, Gever JR, et al. 2013. Pharmacokinetics and metabolism of 2-aminothiazoles with antiprion activity in mice. Pharm Res 30: 932-950.

Sim VL, Caughey B. 2009. Recent advances in prion chemotherapeutics. Infect Disord Drug Targets 9: 81-91.

Song CH, Furuoka H, Kim CL, Ogino M, Suzuki A, Hasebe R, Horiuchi M. 2008. Effect of intraventricular infusion of anti-prion protein monoclonal antibodies on disease progression in prion-infected mice. J Gen Virol 89: 1533 1544.

Stewart LA, Rydzewska LHM, Keogh GF, Knight RSG. 2008. Systematic review of therapeutic interventions in human prion disease. Neurology 70: 1272-1281.

Tagliavini F, McArthur RA, Canciani B, Giaccone G, Porro M, Bugiani M, Lievens PM-J, Bugiani O, Peri E, Dall'Ara P, et al. 1997. Effectiveness of anthracycline against experimental prion disease in Syrian hamsters. Science 276: 1119-1121.

Tagliavini F, Forloni G, Colombo L, Rossi G, Girola L, Canciani B, Angeretti N, Giampaolo L, Peressini E, Awan T, et al. 2000. Tetracycline affects abnormal properties of synthetic PrP peptides and $\operatorname{PrP}^{\mathrm{Sc}}$ in vitro. J Mol Biol 300: 1309-1322.

Terada T, Tsuboi Y, Obi T, Doh-ura K, Murayama S, Kitamoto T, Yamada T, Mizoguchi K. 2010. Less proteaseresistant $\operatorname{PrP}$ in a patient with sporadic CJD treated with intraventricular pentosan polysulphate. Acta Neurol Scand 121: 127-130.

Teruya K, Doh-ura K. 2013. Amyloid-binding compounds and their anti-prion potency. Curr Top Med Chem 13: 2522-2532.

Teruya K, Kawagoe K, Kimura T, Chen C, Sakasegawa Y, Doh-ura K. 2009. Amyloidophilic compounds for prion diseases. Infect Disord Drug Targets 9: 15-22.

Terzano M, Montanari E, Calzetti S, Mancia D, Lechi A. 1983. The effect of amantadine on arousal and EEG patterns in Creutzfeldt-Jakob disease. Arch Neurol 40: 555559.

Todd NV, Morrow J, Doh-ura K, Dealler S, O’Hare S, Farling P, Duddy M, Rainov NG. 2005. Cerebroventricular infusion of pentosan polysulphate in human variant Creutzfeldt-Jakob disease. J Infect 50: 394-396.

Trevitt CR, Collinge J. 2006. A systematic review of prion therapeutics in experimental models. Brain 129: 2241-2265.

Tsuboi Y, Doh-ura K, Yamada T. 2009. Continuous intraventricular infusion of pentosan polysulfate: Clinical trial against prion diseases. Neuropathol 29: 632-636.

Venko K, Župerl Š, Novič M. 2014. Prediction of antiprion activity of therapeutic agents with structure-activity models. Mol Divers 18: 133-148.

Wagner J, Ryazanov S, Leonov A, Levin J, Shi S, Schmidt F, Prix C, Pan-Montojo F, Bertsch U, Mitteregger-Kretzschmar G, et al. 2013. Anle138b: A novel oligomer modulator for disease-modifying therapy of neurodegenerative diseases such as prion and Parkinson's disease. Acta Neuropathol 125: 795-813.

Wang LH, Bucelli RC, Patrick E, Rajderkar D, Alvarez E, Lim MM, DeBruin G, Sharma V, Dahiya S, Schmidt RE, et al. 2013. Role of magnetic resonance imaging, cerebrospinal fluid, and electroencephalogram in diagnosis of sporadic Creutzfeldt-Jakob disease. J Neurol 260: 498-506. 
Insights from Therapeutic Studies for PrP Prion Disease

White AR, Enever P, Tayebi M, Mushens R, Linehan J, Brandner S, Anstee D, Collinge J, Hawke S. 2003. Monoclonal antibodies inhibit prion replication and delay the development of prion disease. Nature 422: 80-83.

White MD, Farmer M, Mirabile I, Brandner S, Collinge J, Mallucci GR. 2008. Single treatment with RNAi against prion protein rescues early neuronal dysfunction and prolongs survival in mice with prion disease. Proc Natl Acad Sci 105: 10238-10243.

Whittle IR, Knight RSG, Will RG. 2006. Unsuccessful intraventricular pentosan polysulphate treatment of variant Creutzfeldt-Jakob disease. Acta Neurochir (Wien) 148: $677-679$.
Will RG, Ironside JW, Zeidler M, Cousens SN, Estibeiro K, Alperovitch A, Poser S, Pocchiari M, Hofman A, Smith PG. 1996. A new variant of Creutzfeldt-Jakob disease in the UK. Lancet 347: 921-925.

Wroe SJ, Pal S, Siddique D, Hyare H, Macfarlane R, Joiner S, Linehan JM, Brandner S, Wadsworth JD, Hewitt P, Collinge J. 2006. Clinical presentation and pre-mortem diagnosis of variant Creutzfeldt-Jakob disease associated with blood transfusion: A case report. Lancet 368: 2061 2067.

Zerr I. 2009. Therapeutic trials in human transmissible spongiform encephalopathies: Recent advances and problems to address. Infect Disord Drug Targets 9: 92-99. 


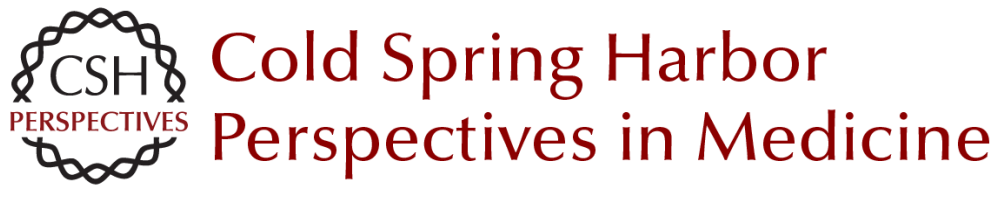

\section{Insights from Therapeutic Studies for PrP Prion Disease}

Kenta Teruya and Katsumi Doh-ura

Cold Spring Harb Perspect Med 2017; doi: 10.1101/cshperspect.a024430 originally published online November 11, 2016

\section{Subject Collection Prion Diseases}

TDP-43 Prions

Takashi Nonaka and Masato Hasegawa

$\alpha$-Synuclein: Multiple System Atrophy Prions Amanda L. Woerman, Joel C. Watts, Atsushi Aoyagi, et al.

Genetics of Synucleinopathies Robert L. Nussbaum

$\beta$-Amyloid Prions and the Pathobiology of

Alzheimer's Disease Joel C. Watts and Stanley B. Prusiner

Disease Mechanisms of C9ORF72 Repeat Expansions Tania F. Gendron and Leonard Petrucelli

Chronic Traumatic Encephalopathy: Is Latency in Symptom Onset Explained by Tau Propagation? Joshua Kriegel, Zachary Papadopoulos and Ann C. McKee

Noncerebral Amyloidoses: Aspects on Seeding, Cross-Seeding, and Transmission Gunilla T. Westermark, Marcus Fändrich, Katarzyna Lundmark, et al.

Structural and Chemical Biology of Presenilin Complexes

Douglas S. Johnson, Yue-Ming Li, Martin

Pettersson, et al.
Cell Biology and Pathophysiology of $\alpha$-Synuclein Jacqueline Burré, Manu Sharma and Thomas C. Südhof

Molecular Mechanisms of Chronic Wasting

Disease Prion Propagation Julie A. Moreno and Glenn C. Telling

Genetics of Amyotrophic Lateral Sclerosis Mehdi Ghasemi and Robert H. Brown, Jr.

The Genetics of C9orf72 Expansions Ilse Gijselinck, Marc Cruts and Christine Van Broeckhoven

Prion-Like Characteristics of Polyglutamine-Containing Proteins Margaret M.P. Pearce and Ron R. Kopito

Therapeutic Strategies for Restoring Tau Homeostasis

Zapporah T. Young, Sue Ann Mok and Jason E. Gestwicki

Fused in Sarcoma Neuropathology in Neurodegenerative Disease Ian R.A. Mackenzie and Manuela Neumann

Experimental Models of Inherited PrP Prion Diseases Joel C. Watts and Stanley B. Prusiner

For additional articles in this collection, see http://perspectivesinmedicine.cshlp.org/cgi/collection/ 